\title{
Serological testing of Schmallenberg virus in Swedish wild cervids from 2012 to 2016
}

\author{
A. Malmsten ${ }^{1 *}$, J. Malmsten ${ }^{2,3}$, G. Blomqvist ${ }^{4}$, K. Näslund ${ }^{4}$, C. Vernersson ${ }^{4}$, S. Hägglund ${ }^{5}$, A.-M. Dalin', \\ E. O. Ågren ${ }^{2}$ and J.-F. Valarcher ${ }^{5,6}$
}

\begin{abstract}
Background: Schmallenberg virus (SBV) first emerged in Europe in 2011, and in Sweden in late 2012. The virus was still circulating in parts of Europe in 2015. In recent testing, the virus has not been detected in Swedish domestic animals, indicating that it is no longer circulating in Sweden. It is not known if the virus has circulated and is still circulating in Swedish wild cervid populations and whether wildlife can act as virus reservoirs. The aim of this study was to investigate whether SBV has circulated, and is still circulating among wild cervids in Sweden.

Results: Ninety-two sera from moose (Alces alces, $n=22$ ), red deer (Cervus elaphus, $n=15$ ), fallow deer (Dama dama, $n=44$ ), and roe deer (Capreolus capreolus, $n=11$ ) were collected and analyzed for antibodies against SBV. The sampling occurred in the southern and middle part of Sweden during three time periods: 1) before the vector season in 2012, 2) after the vector season in 2012, and 3) after the vector season in 2015. Animals from periods 1 and 2 were of varying ages, whereas animals collected in period 3 were born after the vector season 2013. Animals from period 1 $(n=15)$ and $3(n=47)$ were seronegative, but, 53\% (16 of 30) of animals from period 2 were seropositive, determined by SBV competitive ELISA. Samples from period 2 were additionally analyzed for SBV-neutralizing antibodies. Such antibodies were detected in 16/16 SBV-N-antibody-positive, 3/12 negative and 2/2 doubtful sera. The two tests were in accordance at SBV-neutralizing antibody titers of 1:32 or higher.

Conclusion: Our results show that SBV circulated among wild cervids during the vector season of 2012. Three years later, no SBV-antibodies were detected in animals born after the vector season 2013. The likely absence of SBV circulation in Sweden, in contrast to other parts of Europe, might be explained by the annual occurrence of a vector-free season due to climate conditions. Interpretations are limited by the small sample-size, but the results suggest that the SBV competitive ELISA has high specificity but might have slightly lower sensitivity compared to a seroneutralization assay, when using samples from wild cervids.
\end{abstract}

Keywords: SBV, Moose, Roe deer, Red deer, Fallow deer, Serology, Orthobunyavirus, Scandinavia, Wildlife

\section{Background}

When an emerging disease affects an animal or human population, there are often social, economic and welfare consequences. This was the case in 2011 and 2012, when Schmallenberg virus (SBV) was detected in Europe [1]. Initially, clinical signs were observed mainly in cattle, and included diarrhea, pyrexia, and a drop in milk yield. Infection during the first part of gestation was followed by stillbirths and birth defects in the offspring. No relation to any current and known circulating pathogen was identified

\footnotetext{
* Correspondence: anna.malmsten@slu.se

'Department of Clinical Sciences, Division of Reproduction, Swedish

University of Agricultural Sciences, Box 705475007 Uppsala, Sweden

Full list of author information is available at the end of the article
}

[2]. Shortly thereafter, the causative agent was shown to be a novel Orthobunyavirus of the family Bunyaviridae [3] that is transmitted by biting midges (Culicoides spp.) [4]. The virus has the ability to cross the placental barrier and cause lesions in fetuses and neonates [5]. It infects a number of domestic and wild animal species including cattle, sheep, goats [6], alpaca [7] red deer, roe deer [8], fallow deer, moose, bison [9], wild boar [10], dogs [11], and a number of zoo animals [12]. In 2014 and 2015 the virus was still circulating in continental Europe [13, 14]. In Sweden, SBV was first detected in 2012 in domestic animals in the south. The virus spread rapidly north beyond the Arctic Circle, and occurred in high prevalence in tested animals [15]. However, it was not known if the virus 
did circulate (in 2012) or still is circulating in wildlife ruminant populations, and if they could act as reservoirs for the virus [16].

The aim of this study was to investigate if SBV is circulating among wild cervids in Sweden. Two hypotheses were tested: a) SBV-specific serum antibodies can be detected in Swedish wild cervids to the same extent and during the same time periods as SBV was diagnosed in domestic ruminants. b) SBV is still widely circulating in wild ruminant populations, despite likely being absent in the domestic ruminant population.

\section{Methods}

\section{Sampling collection}

Sera from moose (Alces alces, $n=22$ ), red deer (Cervus elaphus, $n=15$ ), fallow deer (Dama dama, $n=44)$, and roe deer (Capreolus capreolus, $n=11$ ) were collected during three time periods: 1 ) before the vector season in 2012 (February, samples collected for biobanking), 2) after the vector season in 2012 (October 2012 - February 2013) and, 3) after the vector season in 2015 (November 2015 - January 2016, see Table 1 for species and sample distribution).

In time period 1, captured live adult moose aged $>2$ years were sampled. In time periods 2 and 3, hunterkilled moose, red deer, fallow deer, and roe deer were sampled. The animals from time period 2 were of varying age. In time period 3 samples were collected from animals that were born after the vector season 2013 and aged between 0.5 to 1.5 years to avoid testing animals that could have been exposed to SBV in earlier time periods.

Age in all sampled species was determined by investigating tooth eruption patterns, and antler development status. All sampling occurred in the southern and middle parts of Sweden (Fig. 1) where domestic ruminants previously had been tested positive for antibodies against SBV [15], whereas recent testing had shown negative results. Blood samples were collected in sterile dry tubes (BD Vacutainer, Franklin Lakes, USA) kept at room temperature $24 \mathrm{~h}$ before centrifugation at $3000 \times \mathrm{g}$ for ten minutes. The sera were stored in $-20{ }^{\circ} \mathrm{C}$ prior to analysis.

\section{Serology}

All sera were analyzed by competitive ELISA (cELISA, ID Screen ${ }^{\circ}$ Schmallenberg virus Competition Multispecies) according to the manufacturer's instructions [17]. This ELISA detects antibodies by competition with conjugated antibodies specific to the SBV nucleoprotein (N). The sera were tested undiluted in duplicate and results were expressed as competition percentage (S/N\%), based on the mean optical density $(\mathrm{OD})_{\text {Sample }} / \mathrm{OD}$ Negative Control X100. As indicated in the instructions, sera with S/N\% greater than $50 \%$ were considered as negative, $>40-50 \%$ were classified as doubtful, and $\leq 40 \%$ as positive. A positive control provided with the kit was included in each run.

Sera collected during the initial SBV outbreak in Sweden [15] (time period 2) were additionally analyzed for SBV-neutralizing antibodies. The sera were heatinactivated, 2-fold diluted from 1:8 to 1:512 and analyzed in duplicate. Fifty microliters of each dilution was mixed with an equal volume of EMEM containing 150 tissue culture infectious dose 50\% $\left(\mathrm{TCID}_{50}\right)$ SBV (BH80/11-4, kindly provided by the Friedrich-Loeffler Institute, Germany) and was incubated for one hour at $37{ }^{\circ} \mathrm{C}$. Thereafter, approximately 20,000 BHK-21 cells in a volume of $50 \mu \mathrm{l}$ in EMEM supplemented with $20 \%$ fetal calf serum were added to each well. The plates were then incubated for 3-4 days at $37{ }^{\circ} \mathrm{C}$ under $5 \% \mathrm{CO}_{2}$. The cells were examined daily in a light microscope for the presence of SBV-specific cytopathogenic effects (cpe). The neutralizing titer of a serum was determined as the highest dilution in which the cell monolayer was intact. A serum sample was considered negative if cpe was observed at and from a dilution of 1:8 $[18,19]$.

\section{Results}

All analyzed samples collected from wild cervids before the vector season $2012(n=15)$ as well as those collected after the vector season 2015 animals $(n=47$, born after the vector season 2013) were seronegative for SBV by cELISA (Table 1). In sera collected during time period 2 after the vector season 2012, SBV-N-specific antibodies were detected by cELISA in 16 sera out of 30

Table 1 Results of serological testing by cELISA of Swedish wild cervids for the detection of specific antibodies directed against Schmallenberg virus in different time periods

\begin{tabular}{llll}
\hline Species & Time period 1 & Time period 2 & Time period 3 \\
& (Feb 2012) & (Nov 2012 - Feb 2013) & (Nov 2015 - Jan 2016) \\
& No. positive/ no. tested (\%) & No. positive/ no. tested (\%) & No. positive/ no. tested (\%) \\
\hline Moose & $0 / 15(0)$ & $3 / 4(75.0)$ & $0 / 3(0)$ \\
Roe deer & & $2 / 6(33.3)$ & $0 / 5(0)$ \\
Red deer & & $0 / 4(25.0)$ & $0 / 11(0)$ \\
Fallow deer & & $11 / 16(75.0)$ & $0 / 28(0)$ \\
Total & $0 / 15(0)$ & $16 / 30(60.0)$ & $0 / 47(0)$ \\
\hline
\end{tabular}




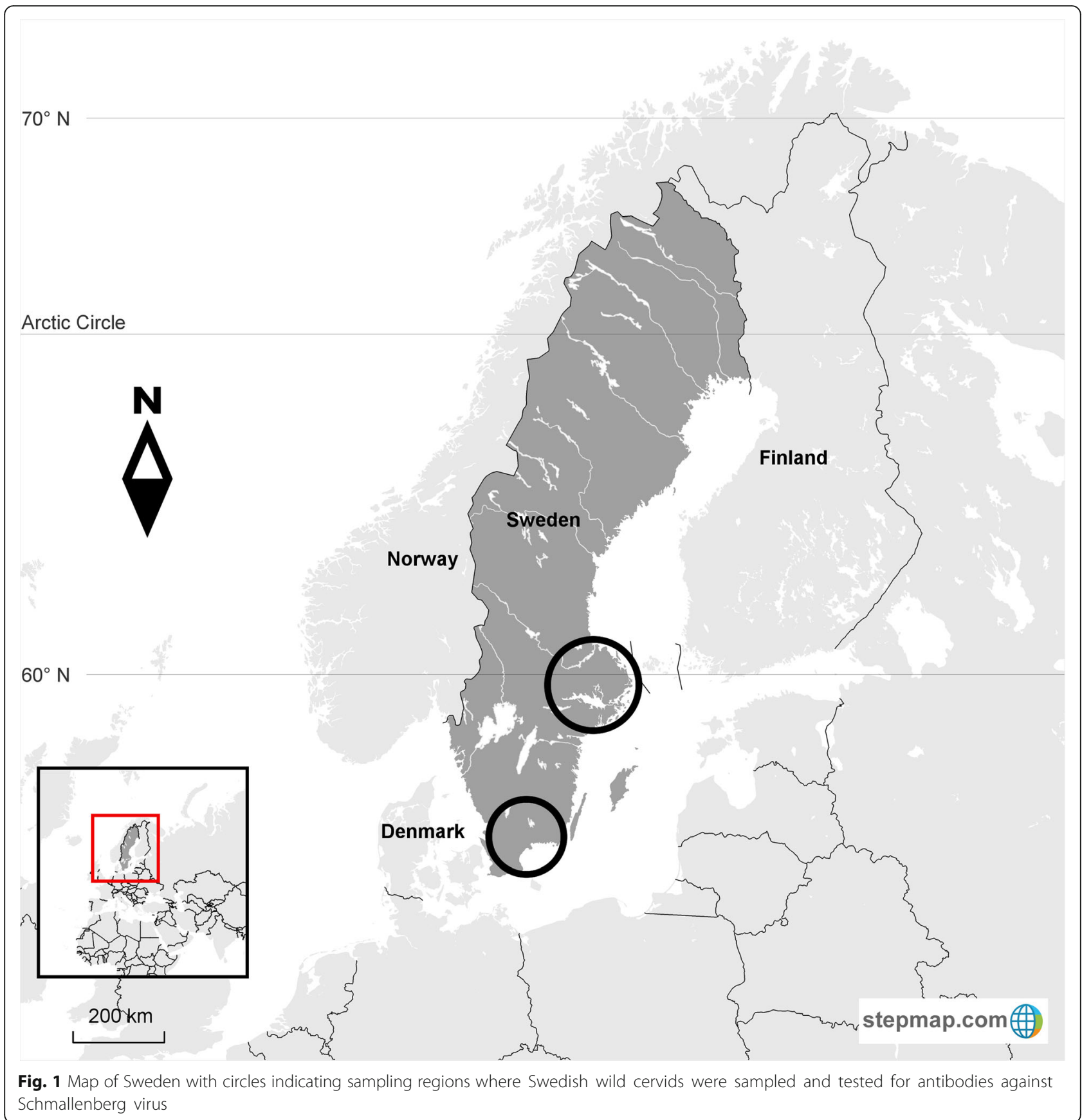

(53\%) (Table 1). One red deer and one fallow deer showed doubtful reaction in cELISA (Table 2).

Sera from time period 2 were additionally analyzed for SBV-neutralizing antibodies. Such antibodies were detected in 16/16 SBV-N-antibody-positive sera, in 3/12 SBV-Nantibody negative and $2 / 2$ doubtful sera. No SBV-specific antibodies were detected by any of the techniques in nine animals (Table 2). Seropositive animals were found in all sampling areas and in all tested cervid species (moose, roe deer, red deer, and fallow deer). The SBV-neutralizing antibody titers varied between species (Table 2), but low sample sizes precluded statistical analyzes with regards to inter- and intraspecies titer variation. These data show a very good agreement between both tests for negative samples or when the SBV-neutralizing antibody titers were $>1$ / 16. Five samples with an SBV-neutralizing antibody titer of $1 / 8(n=3)$ or $1 / 16(n=2)$ were found doubtful $(n=2)$ or negative $(n=3)$ by cELISA.

\section{Discussion}

This is the first report of findings of SBV-specific antibodies in Scandinavian wildlife, showing that wild 
Table 2 Sera from wild cervids sampled in Sweden between November 2012 and February 2013, and tested for SBV antibodies by serum neutralization test (SNT), and competitive ELISA (cELISA)

\begin{tabular}{|c|c|c|c|c|}
\hline \multicolumn{2}{|l|}{$\overline{\text { SNT }}$} & \multicolumn{3}{|l|}{ CELISA } \\
\hline Titer & No & No positive ( $\leq 40 \%)$ & No doubtful (>40-50\%) & No negative (>50\%) \\
\hline$\overline{<8}$ & 9 (3 red deer, 3 fallow deer, 3 roe deer) & - & - & 9 (3 red deer, 3 fallow deer, 3 roe deer) \\
\hline 8 & 7 ( 1 red deer, 4 fallow deer, 2 roe deer) & 4 (3 fallow deer, 1 roe deer $)^{a}$ & 1 (1 red deer) & 2 (1 fallow deer, 1 roe deer) \\
\hline 16 & 6 (1 moose, 4 fallow deer, 1 roe deer) & 4 (3 fallow deer, 1 roe deer $)^{a}$ & 1 ( 1 fallow deer) & 1 (1 moose) \\
\hline 32 & 3 (1 moose, 2 fallow deer) & 3 (1 moose, 2 fallow deer $)^{a}$ & - & - \\
\hline 64 & 5 (2 moose, 3 fallow deer) & 5 (2 moose, 3 fallow deer $)^{\mathrm{a}}$ & - & - \\
\hline
\end{tabular}

${ }^{a}$ Indicates agreement of the results of the two tests

cervids in Sweden were exposed to the virus in the summer of 2012 and probably not after the vector season 2014. Moreover, this study indicates that SBV infection in wildlife and domesticated animals follows the same pattern in the same area in which cattle were seropositive in 2012 and 2013 but seronegative in a recent serological survey when born after the vector season 2013 (S. Zohari, personal communication). Schmallenberg virus does not seem to circulate in Sweden anymore, in contrast to other European countries such as Germany [13]. The difference between Sweden and countries in central and southern Europe is that Sweden has a long vector-free season. Virus transmission and spread is possible at temperatures around $15{ }^{\circ} \mathrm{C}$ with a temperature optimum between $18{ }^{\circ} \mathrm{C}$ and $19{ }^{\circ} \mathrm{C}$ due to vector limitations [20]. In Sweden, such daily mean temperatures are usually limited to May-August [21], but may occur in September as well. Virus persistence depends on the winter survival of adult midges which must have access to a naïve ruminant population. The absence of SBV antibodies in the tested animals suggests that the virus does not persist in ruminants (wild or domestic) or in the environment during the vector-free season. However, to completely verify that the infection is not present in Swedish cervid populations, a larger and predetermined number of animals need to be tested.

A seroneutralization test (SNT) was used at first to test wildlife following the emergence of SBV in Europe, since no cELISA was available to measure specific antibodies against SBV. Since then, a cELISA has been developed with high sensitivity and specificity for domestic ruminant samples [17], and in addition, is easier to perform. Our results indicate that the two methods are in agreement for most samples tested and the level of agreement increases with increasing titer. It is possible that none of the techniques perform well for samples with low titers. Our data suggest that the cELISA lacks sensitivity for sera with low antibody titers. The SNT, on the other hand, might lack specificity for sera at low dilution, as previously observed for sheep [22]. Nevertheless, in contrast to in the sera collected between November 2012 and February 2013, no specific antibodies were detected by cELISA in sera collected in 2015 from animals aged between 0.5 and 1.5 years of age, which suggest that the SBV has not recently circulated among wild cervids in the investigated area.

The effect of SBV in wildlife is still unknown. No clinical signs of SBV were reported in Swedish wildlife during the summer and early autumn of 2012 when the outbreak was detected. Possible signs of SBV infection in Swedish wild or fenced cervids, in the form of abortions and congenital malformations, were not reported during 2013 [23]. However, it is unlikely to make such observations in wild animals for a number of reasons such as scavenging birds and mammals. Furthermore, it requires a primary maternal infection and viremia during a particular period of pregnancy, i.e. after the first placentoma has developed and before the fetuses are immunocompetent [24]. The circulation of SBV most likely did not coincide with the placentoma formation in wild cervids in Sweden. Hence, delayed consequences of SBV infection in Swedish cervids are presumed to be minimal.

\section{Conclusion}

Schmallenberg virus was circulating among Swedish wild cervids during the vector season 2012, but no serological evidence of SBV was found during subsequent testing in 2015 and 2016. Based on Swedish climate conditions and the results of this study, we can assume that Sweden has an unfavorable climate for SBV-overwintering vectors. This might have contributed to the fact that the virus infection has seemingly not become endemic or possibly not reoccurred in Sweden. Midge activity and the reproductive season of Swedish wild cervids, is a seasonal and biological mismatch for the virus, which may explain that SBV has little impact on Swedish wild ruminant health. These animals are thus highly unlikely to be reservoirs of this virus.

\section{Abbreviations}

CELISA: Competitive enzyme-linked immunosorbent assay; CPE: Cytopathogenic effects; N: Nucleoprotein; OD: Optical density; SBV: Schmallenberg virus; SNT: Seroneutralization test; TCID: Tissue culture infectious dose 


\section{Acknowledgements}

The authors are thankful to members of the Swedish Association for Hunting and Wildlife Management and its "wildlife sampling organization" (Viltprovtagarna), Eriksberg Wildlife Park, and the Department of Wildlife, Fish, and Environmental Studies at the Swedish University of Agricultural Sciences in Umeå for supplying the samples for this study. We are also most grateful to the gamekeepers of the two estates that have contributed with additional samples. We also thank Anna Johansson Gordon for language review and editing.

\section{Funding}

This work was supported by the Swedish National Veterinary Institute in Uppsala, Sweden, and by the Department of Clinical Sciences at the Swedish University of Agricultural Sciences in Uppsala, Sweden. Both institutions jointly supported equal amounts of internal funding for time allocated and costs for the design of the study, sample collection, analyzes, interpreting the data, and writing the manuscript.

\section{Availability of data and materials}

Data supporting the results of this article are included within the article.

\section{Authors' contributions}

$A M, J M$, and JFV were involved in the design and coordination of the study, $A M, J M$ and $E \AA$ collected/coordinated the sampling. GB, KN, CV, SH were responsible for the seroneutralization test and ELISA. AM, JM, JFV GB, KN, CV, $\mathrm{SH}, \mathrm{AMD}$, and $\mathrm{E} \AA$ contributed analyzing data and in drafting the manuscript. All authors have read and approved the final manuscript.

\section{Competing interests}

The authors declare that they have no competing interests.

\section{Consent for publication}

Not applicable.

\section{Ethics approval and consent to participate}

The collection of moose samples from 2012 were performed with ethical approval from the Umeå ethics committee on animal welfare (permit no. A12/ 12). Sampling of hunter-harvested animals did not require official or institutional ethical approval according to the Animal Protection Act (1988:534), §1b, Ministry of Enterprise and Innovation (in Swedish).

\section{Publisher's Note}

Springer Nature remains neutral with regard to jurisdictional claims in published maps and institutional affiliations.

\section{Author details}

'Department of Clinical Sciences, Division of Reproduction, Swedish University of Agricultural Sciences, Box 705475007 Uppsala, Sweden. 2Department of Pathology and Wildlife Diseases, National Veterinary Institute, 75189 Uppsala, Sweden. ${ }^{3}$ Department of Wildlife, Fish, and Environmental studies, Swedish University of Agricultural Sciences, 90183 Umeå, Sweden. ${ }^{4}$ Department of Microbiology, National Veterinary Institute, 75189 Uppsala, Sweden. ${ }^{5}$ Department of Clinical Sciences, Host Pathogen Interaction Group, DOS, Swedish University of Agricultural Sciences, Box 705475007 Uppsala, Sweden. ${ }^{6}$ Department of Clinical Sciences, Host Pathogen Interaction Group, Ruminant medicine, Swedish University of Agricultural Sciences, Box 7054750 07 Uppsala, Sweden.

\section{Received: 6 July 2016 Accepted: 28 March 2017}

\section{Published online: 04 April 2017}

\section{References}

1. Spiegel Online 'Schmallenberg-Virus. Neue Tierseuche breitet sich rasant aus. http://www.spiegel.de/wissenschaft/natur/schmallenberg-virus-neuetierseuche-breitet-sich-rasant-aus-a-817671.html. Accessed 1 May 2016 (in German).

2. ProMED-mail: Schmallenberg virus - Europe (26): Vector morphology. March 10: 20120311.1066949. 2012. http://www.promedmail.org. Accessed Mar 82013.

3. Hoffmann B, Scheuch M, Höper D, Jungblut R, Holsteg M, Schirrmeier $H_{\text {, }}$ Eschbaumer M, Goller KV, Wernike K, Fischer M, Breithaupt A, Mettenleiter TC, Beer M. Novel orthobunyavirus in cattle, Europe, 2011. Emerg Infect Dis. 2012;18:469-72. doi:10.3201/eid1803.111905.
4. De Regge N, Deblauwe I, De Deken R, Vantiegheim P, Madder M, Geysen D, Smeets F, Losson B, van den Berg T, Cay AB. Detection of Schmallenberg virus in different Culicoides spp. by real-time RT-PCR. Transbound Emerg Dis. 2012;59:471-5. doi:10.1111/tbed.12000.

5. Garigliany MM, Bayrou C, Kleijnen D, Cassart D, Jolly S, Linden A, Desmecht D. Schmallenberg virus: a new Shamonda/Sathuperi-like virus on the rise in Europe. Antivir Res. 2012;95:82-7. doi:10.1016/j.antiviral.2012.05.014.

6. van den Brom R, Luttikholt SJ, Lievaart-Peterson K, Peperkamp NH, Mars MH, van der Poel WH, Vellema P. Epizootic of ovine congenital malformations associated with Schmallenberg virus infection. Tijdschr Diergeneeskd. 2012;137:106-11.

7. Jack C, Anstaett O, Adams J, Noad R, Brownlie J, Mertens P. Evidence of seroconversion to SBV in camelids. Vet Rec. 2012;170:603. doi:10.1136/vr.e3939.

8. Linden A, Desmecht D, Volpe R, Wirtgen M, Gregoire F, Pirson J, Patemostre J, Kleijnen D, Schirrmejer H, Beer M, Garigliany MM. Epizootic spread of Schmallenberg virus among wild cervids, Belgium, fall 2011. Emerg Infect Dis. 2012;18:2006-8. doi:10.3201/eid1812.121067.

9. Larska M, Krzysiak M, Smreczak M, Polak MP. Zmudsinski. First detection of Schmallenberg virus in elk (Alces alces) indicating infection of wildlife in Bialowieza National Park in Poland. Vet J. 2013;198:279-81. doi:10.1016/j.tvjl.2013.08.013.

10. Mouchantat S, Wernike K, Lutz W, Hoffmann B, Ulrich RG, Börner K, Wittstatt $\mathrm{U}$, Beer M. A broad spectrum screening of Schmallenberg virus antibodies in wildlife animals in Germany. Vet Res. 2015;46. doi: 10.1186/s13567-015-0232-x.

11. Sailleau C, Boogaerts C, Meyrueix A, Laloy E, Bréard E, Viarouge C, Desprat A, Vitour D, Doceul V, Boucher C, Zientara S, Nicolier A, Grandjean D. Schmallenberg virus infection in dogs, France, 2012. Emerg Infect Dis. 2013; 19:1896-8, doi:10.3201/eid1911.130464.

12. Molenaar FM, La Rocca SA, Khatri M, Lopez J, Steinbach F, Dastjerdi A. Exposure of Asian elephants and other exotic ungulates to Schmallenberg virus. PLoS One. 2015;10:e0135532. doi:10.1371/journal.pone.0135532.

13. Wernike K, Hoffmann B, Conraths FJ, Beer M. Schmallenberg virus recurrence, Germany, 2014. Emerg Infect Dis. 2015;21:1202-4. doi:10.3201/eid2107.150180.

14. Poskin A, Théron A, Hanon JB, Saegerman C, Vervaeke M, Van der Stede Y, Cay B, De Regge N. Reconstruction of the Schmallenberg virus epidemic in Belgium: Complementary use of disease surveillance approaches. Vet Microbiol. 2016;183:50-61. doi:10.1016/j.vetmic.2015.11.036. Epub 2015 Nov 30

15. Chenais E, Ståhl K, Frössling J, Blomqvist G, Näslund K, Svensson L, Renström L, Mieziewska K, Elvander M, Valarcher JF. Schmallenberg virus beyond latitude $60^{\circ} \mathrm{N}$. Transbound Emerg Dis. 2013;62:11-8.

16. Talavera S, Muñoz-Muñoz F, Durám M, Verdún M, Soler-Membrives A, Oleaga Á, Arenas A, Ruiz-Fons F, Estrada R, Pagès N. Culicoides species communities associated with wild ruminant ecosystems in Spain: tracking the way to determine potential bridge vectors for arboviruses. PLoS One. 2015;28: e0141667. doi:10.1371/journal.pone.0141667. eCollection 2015

17. Comtet L, Pourquier, P. (IDvet, France). ID Screen ${ }^{\oplus}$ Schmallenberg virus Competition Multi-species: validation of a competitive ELISA for the detection of antibodies directed against the Schmallenberg virus nucleoprotein. Brussels, Belgium: Poster presented at the Epizone 7th Annual Meeting; 2013. doi: 10.1038/nplants.2017.32.

18. Näslund K, Blomqvist G, Vernersson C, Zientara S, Bréard E, Valarcher JF. Development and evaluation of an indirect enzyme-linked immunosorbent assay for serological detection of Schmallenberg virus antibodies in ruminants using whole virus antigen. Acta Vet Scand. 2014;56:71. doi:10.1186/ s13028-014-0071-1.

19. van der Poel WH, Cay B, Zientara S, Steinbach F, Valarcher JF, Bøtner A, Mars $\mathrm{MH}$, Hakze-van der Honing R, Schirrmeier H, Beer M. Limited interlaboratory comparison of Schmallenberg virus antibody detection in serum samples. Vet Rec. 2014;174:380. doi:10.1136/vr.102180. Epub 2014 Mar 3

20. EFSA (European Food Safety Authority). "Schmallenberg" virus: Analysis of the epidemiological data and Impact assessment. http://www.efsa.europa. eu/en/efsajournal/doc/2768.pdf. Accessed 10 Mar 2013.

21. Climatemps.com, 2013: Sweden climate graph. http://www.sweden. climatemps.com/\#brief. Accessed 10 Mar 2013.

22. Loeffen W, Quak S, de Boer-Luijtze E, Hulst M, van der Poel W, Bouwstra R, Maas R. Development of a virus neutralisation test to detect antibodies against Schmallenberg virus and serological results in suspect and infected herds. Acta Vet Scand. 2012:54:44. doi:10.1186/1751-0147-54-44.

23. Statens veterinärmedicinska anstalt. Sjukdomsövervakning av vilda djur i Sverige 2014. SVA:S Rapportserie 31 ISSN 1654-7098 (in Swedish).

24. Garigliany MM, Bayrou C, Kleijnen D, Cassart D, Desmecht D. Schmallenberg virus in domestic cattle, Belgium, 2012. Emerg Infect Dis. 2012;18:1512-4. doi:10.3201/eid1809.120716. 